\title{
Éric Marty, Pourquoi le Xx siècle a-t-il pris Sade au sérieux?
}

\section{Francesca Milaneschi}

\section{(2) OpenEdition}

\section{Journals}

\section{Edizione digitale}

URL: http://journals.openedition.org/studifrancesi/3866

DOI: 10.4000/studifrancesi.3866

ISSN: 2427-5856

\section{Editore}

Rosenberg \& Sellier

\section{Edizione cartacea}

Data di pubblicazione: 1 décembre 2012

Paginazione: 611-612

ISSN: 0039-2944

\section{Notizia bibliografica digitale}

Francesca Milaneschi, «Éric Marty, Pourquoi le xx siècle a-t-il pris Sade au sérieux?», Studi Francesi [Online], 168 (LVI | III) | 2012, online dal 30 novembre 2015, consultato il 05 mars 2021. URL: http:// journals.openedition.org/studifrancesi/3866 ; DOI: https://doi.org/10.4000/studifrancesi.3866

Questo documento è stato generato automaticamente il 5 mars 2021.

\section{@(@) $\Theta \Theta$}

Studi Francesi è distribuita con Licenza Creative Commons Attribuzione - Non commerciale - Non opere derivate 4.0 Internazionale. 


\title{
Éric Marty, Pourquoi le $\mathrm{XX}^{e}$ siècle a-t-il pris Sade au sérieux?
}

\author{
Francesca Milaneschi
}

\section{NOTIZIA}

ÉRIC MARTY, Pourquoi le XX ${ }^{\mathrm{e}}$ siècle a-t-il pris Sade au sérieux?, Paris, Seuil, 2011 («Fiction \& (ie»), pp. 245.

$1 \quad$ Il saggio di Éric Marty sulla ricezione novecentesca di Sade si suddivide in tre macrosezioni, rispettivamente intitolate: «La fondation du sujet sadien», «Le dialogue avec le sujet sadien» e infine «L'usage du sujet sadien». Il lettore si ritrova impegnato per più di quattrocento pagine a ripercorrere l'affascinante avventura della fortuna sadiana nel secolo appena trascorso, passando per Hegel, Kojève e poi Adorno, da Klossowski a Bataille e Blanchot, da Lautréamont a Kafka, partendo da Rousseau per approdare a Lévinas, senza dimenticare Foucault, Freud, Lacan, Deleuze, Barthes, Sacher-Masoch e «Tel-Quel», per arrestarsi alfine sull'ultimo Pasolini, che sembra mettere un punto di non ritorno al dialogo del Novecento con Sade.

2 Spiace soltanto l'assenza di un indice analitico che avrebbe consentito di verificare con certezza l'assenza del nome di Albert Camus - e delle sue pagine su Sade nel nome della révolte métaphysique all'interno dell'Homme révolté del 1951 - da questo Novecento francese dei Modernes. Camus infatti, non ignorando né Klossowski né Blanchot, ha forse il torto di porgere una lettura dell'opera di Sade, piuttosto che servirsi del nome "Sade" come feticcio culturale, ideologico, politico e, last but not least, letterario. Lo ricordava del resto anche Macchia, nel suo Mito di Parigi: se l'Ottocento francese si vergognava di Sade, il Novecento comincia invece a vantarsene, nonché a pubblicare l'edizione completa delle sue opere. Ecco quindi emergere gli epigoni di Sade o gli autori di sadiani pastiches, come il Sollers reo confesso di Contre l'Être suprême, e tanti altri autori e autrici, soprattutto dell'ultimo quarto del secolo scorso. 
3 Tale e tanta è la suggestione che il divin marchese esercita sul secolo dell'olocausto, che essa fa dire a Camus, in pieno esistenzialismo: «Quand la comptabilité est close, quand toutes les victimes ont été massacrées, les bourreaux restent face à face, dans le château solitaire». E tale e tanta era la consapevolezza che Sade ebbe dell'opera che stava scrivendo, quella sì davvero degna della "Modernità", da mettere in bocca al duca de Blanchis le parole: "Vous êtes déjà mortes au monde». Larvatus prodeo, direbbe Roland Barthes. Ed è sempre l'illeggibile Sade, con le sue teorie e i suoi sofismi, con i suoi tòpoi ossessivi ideati per dimostrarli (per esempio il tema del "castello"), con il suo inferno politico, sociale e soprattutto umano, che Camus legge ed interpreta, preceduto, certo, dalla Préface di Jean Pau-lhan a Justine ou Les infortunes de la vertu, datata 1945 e anch'essa qui ignorata dal professor Marty nella sua portata illuminante sull'intera opera sadiana.

4 La lettura in senso "sado-masochista" che Deleuze, - con la sua ruse, certo, ma anche con la sua ironica grazia - offre di Sade, è già presente in nuce in Camus, misconosciuto dai Moderni in nome della supremazia esistenzialista della "filosofia" sulla "morale", ove afferma: «Le maître accepte d'être à son tour esclave et peut-être même le désire. "L'échafaud serait pour moi le trône des voluptés"». E già Camus aveva riconosciuto Sade come feticcio, la cui effigie è stata condannata al patibolo, pur non avendo perpetrato omicidi, se non con la fantasia: da letterato ideale, Sade edifica una finzione per darsi l'illusione di essere. 